\title{
New Insights into the Self-Assembly of Insulin Amyloid Fibrils: an H/D-Exchange FT-IR Study
}

\section{Running title: "H/D-exchange in insulin amyloid probed by FT-IR-spectroscopy"}

\author{
Wojciech Dzwolak $^{a^{*}, b}$, Anna Loksztejn ${ }^{a, b}$, Vytautas Smirnovas ${ }^{a \S}$ \\ ${ }^{a}$ Institute of High Pressure Physics, Polish Academy of Sciences, Sokolowska 29/37, 01-142 Warsaw, Poland, \\ ${ }^{b}$ Department of Chemistry, Warsaw University, Pasteura 1, 02-093 Warsaw, Poland, \\ $\S$ Present address: University of Dortmund, Department of Chemistry, Physical Chemistry I - Biophysical \\ Chemistry, Otto-Hahn Str. 6, D-44227 Dortmund, Germany \\ * Corresponding author: \\ Phone: +48 22888 0237; Fax: +48 22632 4218; \\ E-mail: wdzwolak@unipress.waw.pl
}

\section{$\underline{\text { Supplementary Information }}$}

The mid-infrared spectra of light $\left(\mathrm{H}_{2} \mathrm{O}\right)$ and heavy $\left(\mathrm{D}_{2} \mathrm{O}\right)$ water are shown in Suppl_Figure_A. The pronounced spectral differences consist in red-shifts of both the stretching and deforming vibrations upon deuteration. The deforming (bending) vibrations of $\mathrm{H}_{2} \mathrm{O}$ and $\mathrm{D}_{2} \mathrm{O}$ are observed at 1638 and 1205 $\mathrm{cm}^{-1}$, respectively (for the pure species - [Suppl_1]). The "hopping", i.e. dynamic interchange of water's hydrogen atoms is visible, when the two species $\left(\mathrm{H}_{2} \mathrm{O}\right.$ and $\left.\mathrm{D}_{2} \mathrm{O}\right)$ are mixed in solution. The bending vibrations of the newly formed molecular entity: "HDO" give rise to a peak at $1450 \mathrm{~cm}^{-1}$. Fractions of $\mathrm{H}_{2} \mathrm{O}, \mathrm{D}_{2} \mathrm{O}$, and $\mathrm{HDO}$ are controlled according to the rapid equilibrium: $\mathrm{H}_{2} \mathrm{O}+\mathrm{D}_{2} \mathrm{O} \Leftrightarrow 2$ HDO. The experimental values of the equilibrium constant:

$$
\mathrm{K}_{e}\left(\equiv[\mathrm{HDO}]^{2} /\left(\left[\mathrm{H}_{2} \mathrm{O}\right] \cdot\left[\mathrm{D}_{2} \mathrm{O}\right]\right)\right.
$$


range from 3.76 to 3.94 approaching the theoretical value of 4 [Suppl_1]. The appearance of the HDO bending band in the $\mathrm{H}_{2} \mathrm{O}+\mathrm{D}_{2} \mathrm{O}$ mixtures occurs at a dramatic expense of intensities of the original $\mathrm{H}_{2} \mathrm{O}$, and $\mathrm{D}_{2} \mathrm{O}$ bending bands (Suppl_Figure_A), which reflects the quadratic inter-dependencies of their fractions according to the equilibrium (Suppl_Figure_B). Upon the mixing, the spectral positions of the three bands change slightly, depending on relative isotopic fractions, which can be explained in terms of nearest-neighbor interactions [Suppl_1]. The rapid decrease of intensities of the $\mathrm{H}_{2} \mathrm{O}$, or $\mathrm{D}_{2} \mathrm{O}$ bending bands upon isotopic dilutions can be advantageous for removal of undesirable spectral components (e.g. $\mathrm{H}_{2} \mathrm{O}$ band, which overlaps amide I band - [Suppl_2]), or for detection of trapped, and therefore nonexchanged water molecules, as is done in this work.

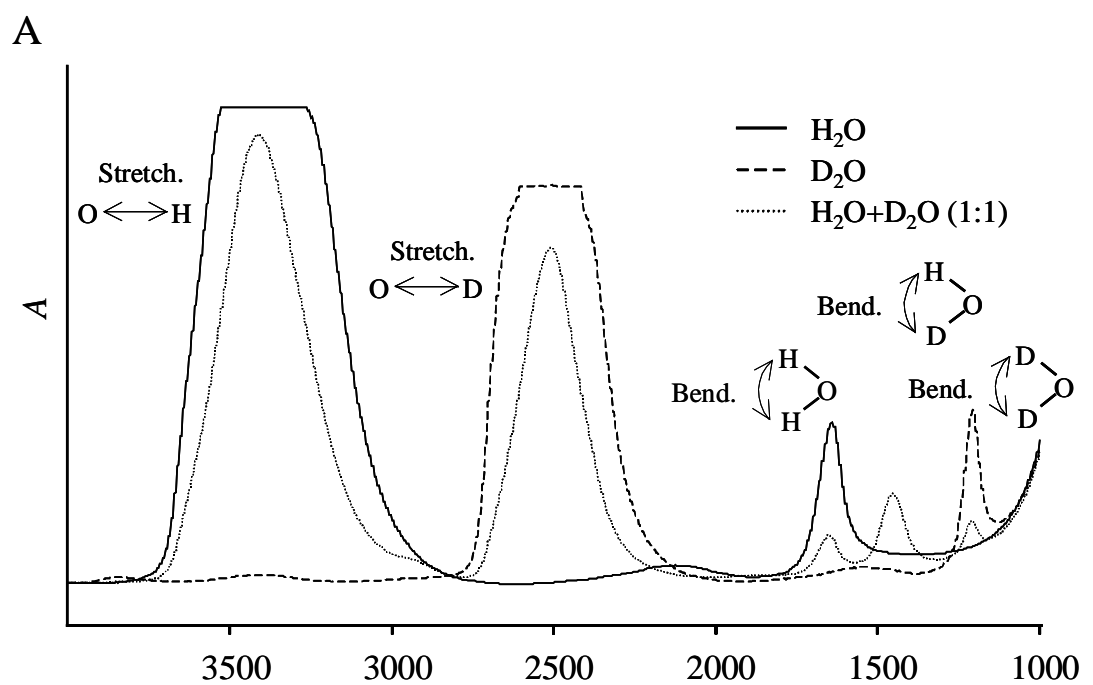

B

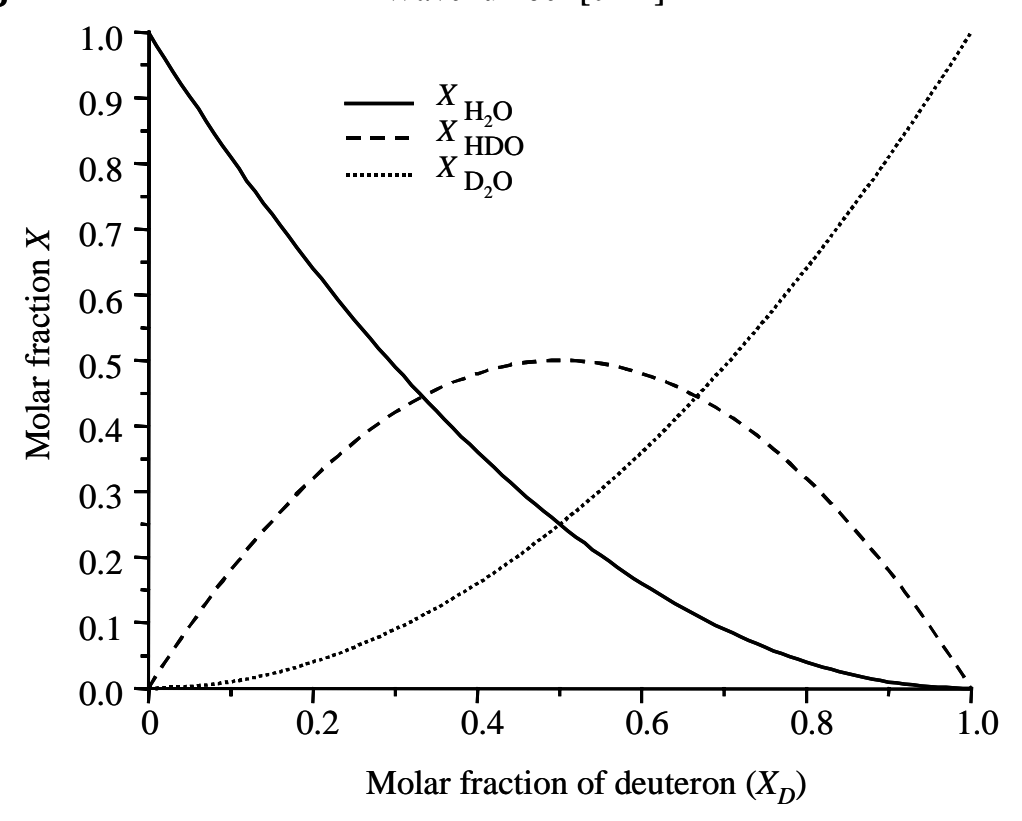




\section{References}

[Suppl_1] Max, J. J., and Chapados, C. (2002) Isotope effects in liquid water by infrared spectroscopy,

J. Chem. Phys. 116, 4626-4642,

[Suppl_2] Zuber, G., Prestrelski, S. J., and Benedek, K. (1992) Application of Fourier transform infrared spectroscopy to studies of aqueous protein solutions, Anal Biochem. 207, 150-156 